\title{
Propofol induces ROS-mediated intrinsic apoptosis and migration in triple-negative breast cancer cells
}

\author{
HAO WANG ${ }^{1,2^{*}}$, LIDONG ZHAO ${ }^{3 *}$, JING WU $^{4}$, JIANG HONG $^{3}$ and SONGPO WANG ${ }^{1}$ \\ ${ }^{1}$ Department of Traditional Chinese Medicine, The General Hospital Affiliated to Shanghai Jiaotong University, \\ Shanghai 200080; ${ }^{2}$ Department of Pneumology, Yancheng TCM Hospital Affiliated to Nanjing University of Chinese \\ Medicine, Yancheng, Jiangsu 224003; ${ }^{3}$ Department of Internal and Emergency Medicine, The General Hospital Affiliated to \\ Shanghai Jiaotong University; ${ }^{4}$ School of Pharmacy, Shanghai Jiaotong University, Shanghai 200080, P.R. China
}

Received August 10, 2018; Accepted April 3, 2020

DOI: $10.3892 / \mathrm{ol} .2020 .11608$

\begin{abstract}
Propofol is widely applied in general anesthesia owing to its short effect and rapid recovery. Apart from its anesthetic advantages, propofol has also been observed to inhibit the growth of several types of cancer cells. Breast cancer is the most diagnosed cancer in females worldwide and triple negative breast cancer (TNBC) constitutes $15-20 \%$ of all breast cancer cases. TNBC is characterized by a high recurrence rate, which is associated with its high mortality rate. The present study aimed to evaluate apoptosis in MDA-MB-468 cells treated with propofol. The Cell Counting Kit- 8 assay was used to assess proliferation in cells treated with different concentrations of propofol. In addition, Annexin V-FITC was used to detect apoptosis. Furthermore, the generation of reactive oxygen species (ROS) was examined. The relative expression of proteins in the intrinsic apoptosis pathway, such as Bak, Bax, Bcl-2, Cytochrome $c$, apoptotic peptidase-activating factor 1 (Apaf-1), Caspase 3 and Caspase 9, were calculated relative to GAPDH with western blot analysis. A wound healing assay was performed to examine the effect of propofol on MDA-MB-468 cell migration. The present study revealed that propofol inhibited the proliferation and increased the level of ROS in MDA-MB-468 cells. The expression levels of Cytochrome $c$, Apaf-1, Bax, Bak and cleaved Caspase 3/9 were upregulated compared with GAPDH. The level of Bcl-2 protein was upregulated by propofol at a concentration of $5 \mu \mathrm{M}$
\end{abstract}

Correspondence to: Professor Jiang Hong, Department of Internal and Emergency Medicine, The General Hospital Affiliated to Shanghai Jiaotong University, 100 Haining Road, Shanghai 200080, P.R. China

E-mail: jhong.pku@163.com

Professor Songpo Wang, Department of Traditional Chinese Medicine, The General Hospital Affiliated to Shanghai Jiaotong University, 100 Haining Road, Shanghai 200080, P.R. China

E-mail: 13386259791@163.com

*Contributed equally

Key words: propofol, intrinsic apoptosis, reactive oxygen species, migration, triple negative breast cancer and downregulated at concentrations of 10 and $20 \mu \mathrm{M}$. In the wound-healing assay, propofol reduced the scratch distance and area. Taken together, the results of the present study suggested that propofol may induce ROS-mediated intrinsic apoptosis and promote migration in TNBC cells.

\section{Introduction}

Triple-negative breast cancer (TNBC) has distinct pathological features and poor prognosis due to the negative expression of the estrogen receptor (ER), progesterone receptor (PR) and human epidermal growth factor receptor-2 (HER-2) (1). Due to its high aggression, the presently available therapies have limited efficacy (2). TNBC comprises $15-20 \%$ of all newly-diagnosed breast cancer cases; however, TNBC accounts for a disproportionate number of breast cancer-associated mortalities, and is responsible for up to $5 \%$ of all cancer mortalities annually (3). Notably, the majority of the available studies on TNBC have been conducted in a Western population (4-6); however, TNBC has been reported to occur more frequently in African women. Therefore, identifying effective therapeutics against TNBC remains an urgent challenge. Although genomic profiling of TNBC has shown promise in aiding clinicians to develop personalized targeted agents against TNBC, this research is still in its infancy, and requires more development, prior to its widespread application in a clinical setting (7). At present, surgery, radiotherapy and chemotherapy are the primary treatments for TNBC; however, due to the complexity of the disease, and the rate of recurrence, the curative effects are not satisfactory (8).

Propofol has been used in surgery since 1977, and was created by Kay and Rolly (9). Due to advantages such as less toxicity, rapid induction of anesthesia and no accumulation in vivo, propofol is widely applied in general anesthesia (10). Experimental evidence has revealed that, not only does propofol have multiple anesthetic advantages, it also exerts a number of non-anesthesia effects (11), and the anti-tumor effect of propofol has been confirmed by numerous researchers $(12,13)$. A previous study demonstrated that propofol actively inhibits proliferation and induces apoptosis in chronic myeloid leukemia KBM-7, KU812 and K562 cells (13). In addition, a previous report has revealed that 
propofol can inhibit the invasion and growth of ovarian cancer ES-2 cells by downregulating the expression of matrix metalloproteinase (MMP)-9 (14). Yang et al (15) suggested that propofol exerts an inhibitory effect on the growth and survival of gastric cancer cells by interfering with the degradation of inhibitor of growth family member 3 (ING3). In pancreatic cancer cells, propofol attenuates cell growth and invasion by inhibiting miR-21 and Slug in a dose- and time-dependent manner (16). Furthermore, extensive evidence has indicated that, in chronic breast cancer, propofol may serve as a novel therapeutic, that functions by inhibiting $\mathrm{NF}-\kappa \mathrm{B}$ and reducing MMP-2 and MMP-9 (17). In brief, propofol effectively influences several biological processes in the development of cancer, by regulating microRNAs and long non-coding RNAs and modulating signaling pathways, such as hypoxia inducible factor 1 subunit $\alpha, \mathrm{MAPK}, \mathrm{NF}-\kappa \mathrm{B}$ and NF-E2-related factor 2 pathways, which are essential for cell proliferation, invasion and apoptosis (18-20).

It has previously been reported that treatment of MDA-MB-231 cells with propofol resulted in increased cell proliferation and migration in a dose- and time-dependent manner (21). However, other researchers have hypothesized that propofol-induced cell migration and the suppression of invasion are partially mediated by downregulating H19 imprinted maternally expressed transcript (H19) in MDA-MB-231 cells in vitro (22). It is surprising that it shows an opposite effect in the same cell line. Therefore, the present study detected the effect of propofol on TNBC cells. The choice of anesthesia protocol has a specific relationship with the recurrence and metastasis of postoperative tumors (23); however, this mechanism has yet to be completely elucidated. Consequently, the role of propofol in TNBC cells remains unclear, and the aim of the present study was to investigate and explain how propofol influences TNBC cells.

\section{Materials and methods}

Reagents. Propofol was purchased from MedChemExpress and was dissolved in dimethyl sulfoxide (DMSO). DMSO was diluted at 1:1,000 in culture medium. N-acetyl-L-cysteine (NAC), which was purchased from Beyotime Institute of Biotechnology, was dissolved in the culture medium at a working concentration of $5 \mathrm{mM}$.

Cell lines and culture. The human triple-negative breast cancer MDA-MB-468 cell line was purchased from the Shanghai Cell Collection. MDA-MB-468 cells were cultured in Ham's F-12K (Kaighn's) Medium (Gibco; Thermo Fisher Scientific, Inc.) with L-glutamine, supplemented with 10\% FBS (Gibco; Thermo Fisher Scientific, Inc.) and $100 \mathrm{U} \mathrm{ml}^{-1}$ penicillin at $37^{\circ} \mathrm{C}$ in a $5 \% \mathrm{CO}_{2}$ humidified atmosphere. Trypsin $(0.02 \%) /$ EDTA $(0.02 \%)$ solution was used when the confluence reached $>80 \%$. Aseptic technique was applied in all experiments.

Cell proliferation assay. The Cell Counting Kit-8 (CCK-8) assay (Dojindo Molecular Technologies, Inc.) was utilized to assess the cell proliferation of MDA-MB-468 cells according to the manufacturer's protocol. The MDA-MB-468 cells were seeded in 96-well plates at a density of $2 \times 10^{4}$ cells/well. Cell confluency was permitted to reach $\sim 80 \%$, and the medium was replaced with fresh medium containing $0.1 \%$ DMSO or varying concentrations of propofol $(0,5,10$ and $20 \mu \mathrm{M})$ or $20 \mu \mathrm{M}$ propofol with $5 \mathrm{mM}$ NAC. The cells were then incubated for $24 \mathrm{~h}$, and a total of $10 \mu \mathrm{l} \mathrm{CCK}-8$ solution was added to the cultures for $2 \mathrm{~h}$ at $37^{\circ} \mathrm{C}$. The absorbance was measured at wavelength of $450 \mathrm{~nm}$ with an automatic enzyme analyzer. All experiments were performed in triplicate. The results are presented as the percentages of live cells over control cells.

Apoptosis assay. The Annexin V-FITC apoptosis detection kit (BD Biosciences) was used to detect cell apoptosis according to the manufacturer's protocol. Briefly, cells were treated with different concentrations of propofol $(0,5,10$ and $20 \mu \mathrm{M})$ or $20 \mu \mathrm{M}$ propofol with $5 \mathrm{mM}$ NAC for $24 \mathrm{~h}$ and washed twice with PBS. Subsequently, cells were stained with $5 \mu$ l Annexin $\mathrm{V}$ and $5 \mu \mathrm{l}$ propidium iodide (BD Biosciences) for $15 \mathrm{~min}$ at room temperature. The cells were analyzed using a flow cytometer (BD Biosciences) and the percentage of apoptotic cells was determined using CellQuest software version 7.5.3 (BD Biosciences).

Measurement of the generation of reactive oxygen species (ROS). The ROS assay kit (Beyotime Institute of Biotechnology) was used to detect the intracellular ROS. MDA-MB-468 cells were plated in 6-well plates at a density of $2 \times 10^{4}$ cells/well and incubated for $24 \mathrm{~h}$ at $37^{\circ} \mathrm{C}$ Following treatment with various concentrations of propofol $(0,5,10$ and $20 \mu \mathrm{M})$ or $20 \mu \mathrm{M}$ propofol with $5 \mathrm{mM} \mathrm{NAC}$ for $24 \mathrm{~h}$ at $37^{\circ} \mathrm{C}$, cells were washed with PBS three times and incubated with $10 \mu \mathrm{M}$ DCFH-DA in serum-free medium for $25 \mathrm{~min}$ at $37^{\circ} \mathrm{C}$ in the dark. The cells were then washed with PBS three times to remove excess DCFH-DA that was unable to fully penetrate the cells. The cells were subsequently fixed in $4 \%$ paraformaldehyde for $30 \mathrm{~min}$ at room temperature, and observed under an inverted fluorescence microscope (magnification, x200).

Wound healing assay. A wound healing assay was performed to examine the effect of propofol on MDA-MB-468 cell migration. Briefly, MDA-MB-468 cells were seeded in 6-well plates containing medium supplemented with $10 \%$ FBS and allowed to form an $80 \%$ confluent cell monolayer. A scratch was made using a $200 \mu \mathrm{l}$ pipette tip and the complete medium was replaced with serum-free medium. The cells were subsequently incubated with various concentrations of propofol $(0$ or $20 \mu \mathrm{M})$ or $20 \mu \mathrm{M}$ propofol with $5 \mathrm{mM}$ NAC for 24 and $48 \mathrm{~h}$ at $37^{\circ} \mathrm{C}$. In order to evaluate wound healing, the scratch area was monitored under an inverted Leica phase-contrast microscope (Leica DFC 300 FX; Leica Microsystems, Inc.), calculated using ImageJ software version 1.52a (National Institutes of Health) and analysed using GraphPad Prism software (version 5; GraphPad Software, Inc.). The assay was performed in triplicate.

Western blot analysis. MDA-MB-468 cells were treated with different concentrations of propofol $(0,5,10$ and $20 \mu \mathrm{M})$ for $24 \mathrm{~h}$ at $37^{\circ} \mathrm{C}$. Subsequently, total protein was extracted from cells using the RIPA kit and protein concentrations were quantified using the BCA protein quantification kit (both from Beyotime Institute of Biotechnology). A total of $30 \mu \mathrm{g}$ protein/lane was separated via SDS-PAGE on a $10 \%$ gel and transferred onto polyvinylidene difluoride membranes. The 


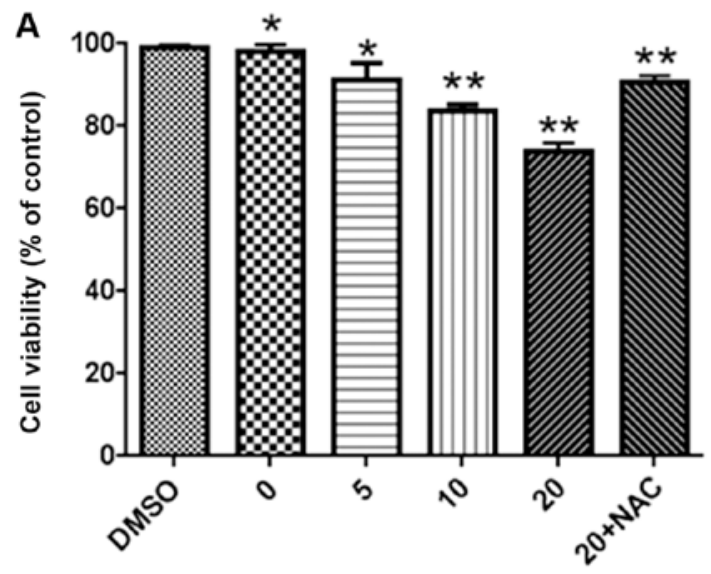

Concentration of propofol $(\mu \mathrm{M})$

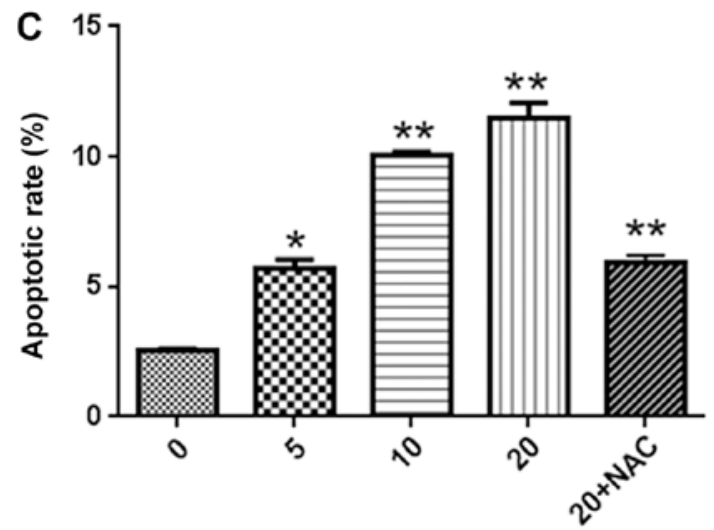

B

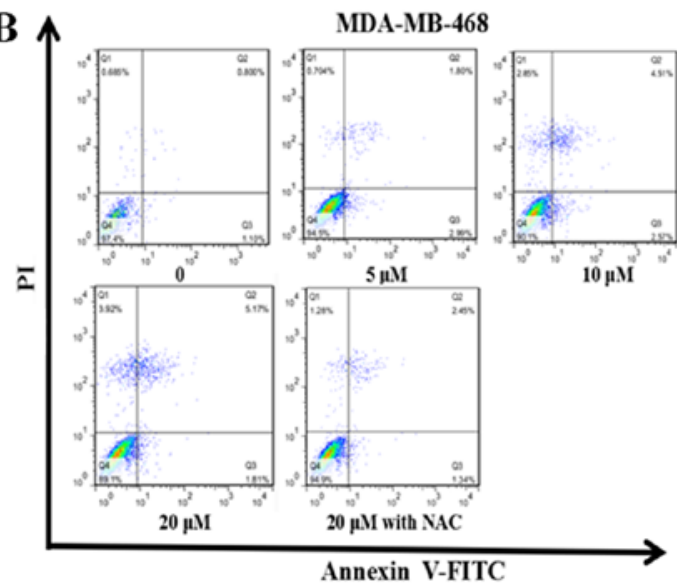

Concentration of propofol $(\mu \mathrm{M})$

Figure 1. Propofol inhibits cell proliferation and induces apoptosis in human triple negative breast cancer cells. (A) A Cell Counting Kit- 8 assay was conducted to detect cell proliferation after exposure to propofol for $24 \mathrm{~h}$. Propofol inhibited the proliferation of MDA-MB-468 cells in a dose-dependent manner. (B) Apoptosis in cells treated with propofol was tested using an Annexin V-FITC and PI staining assay and flow cytometry. The rate of apoptosis in cells treated with propofol $(5,10,20$ and $20 \mu \mathrm{M}+\mathrm{NAC})$ for $24 \mathrm{~h}$ was $5.5,9.5,10.1$ and $5.1 \%$, respectively. (C) The percentage of apoptotic cells in each treatment group was quantified. Values are reported as the mean $\pm \mathrm{SD}(\mathrm{n}=3)$. ${ }^{*} \mathrm{P}<0.05$ and $^{* *} \mathrm{P}<0.01$ vs. the control group. PI, propidium iodide; NAC, N-acetyl-L-cysteine.

membranes were blocked with 5\% skim milk in TBST for $1 \mathrm{~h}$ at room temperature, prior to incubation with primary antibodies against: Caspase 3 (cat. no. sc-5273; 1:1,000; Santa Cruz Biotechnology, Inc.), Caspase 9 (cat. no. sc-56076; 1:1,000; Santa Cruz Biotechnology Inc.), Bax (cat. no. sc-7480; 1:1,000; Santa Cruz Biotechnology Inc.), Bak (cat. no. 12105; 1:1,000; Cell Signaling Technology, Inc.), Bcl-2 (cat. no. 15071; 1:1,000; Cell Signaling Technology, Inc.), cytochrome c (cat. no. 11940; 1:1,000; Cell Signaling Technology, Inc.) Apaf-1 (cat. no. 8969; 1:1,000; Cell Signaling Technology, Inc.) and GAPDH (cat. no. 5174; 1:5,000; Cell Signaling Technology, Inc.) overnight at $4^{\circ} \mathrm{C}$. Membrane was washed three times with TBST and subsequently incubated with anti-rabbit (cat. no. sc-2030) or anti-mouse (cat. no. sc-2031) secondary antibodies (both 1:5,000 and from Santa Cruz Biotechnology, Inc.) for $2 \mathrm{~h}$ at room temperature. Protein bands were visualized using the enhanced chemiluminescence reagent (BD Biosciences) and analyzed using Image Lab software v3.0 (Bio-Rad Laboratories, Inc.).

Statistical analysis. The data are presented as mean \pm standard deviation. Statistical analyses were performed using SPSS software (v20; IBM Corp.). The Student's t-test was used to detect the difference between two groups. The one-way ANOVA followed by Tukey's post hoc test was used to compare several groups. $\mathrm{P}<0.05$ was considered to indicate a statistically significant difference.

\section{Results}

Effect of propofol on MDA-MB-468 cell proliferation and apoptosis. MDA-MB-468 cells were treated with $0.1 \%$ DMSO or propofol $(5,10$ and $20 \mu \mathrm{M})$ or $20 \mu \mathrm{M}$ propofol with $5 \mathrm{mM}$ NAC for $24 \mathrm{~h}$. As illustrated in Fig. 1A, propofol significantly decreased cell proliferation in a concentration-dependent manner, and this effect was reversed, following treatment with 5 mM NAC $(\mathrm{P}<0.05)$. Additionally, treatment with $0.1 \%$ DMSO did not affect cell viability (Fig. 1A). Apoptosis was detected MDA-MB-468 cells using an Annexin V-FITC apoptosis detection kit and flow cytometry. The rates of apoptosis following treatment with 5, 10 and $20 \mu \mathrm{M}$ propofol for $24 \mathrm{~h}$ were $5.5 \pm 2.1,9.9 \pm 3.4$ and $10.9 \pm 2.9 \%$, respectively, and were significantly increased compared with control cells $(2.6 \pm 1.5 \% ; \mathrm{P}<0.05)$. Furthermore, treatment with $5 \mathrm{mM}$ NAC was revealed to attenuate apoptosis induced by $20 \mu \mathrm{M}$ propofol (Fig. 1B and C). 


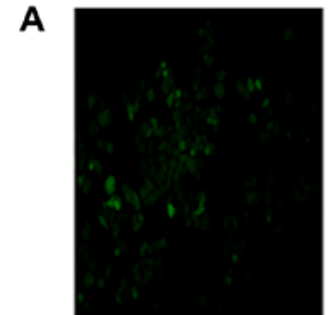

Propofol 0

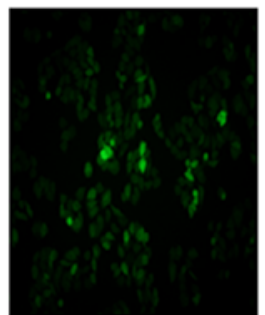

$5 \mu \mathrm{M}$

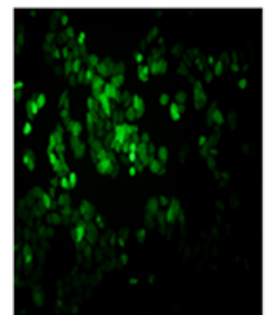

$10 \mu \mathrm{M}$

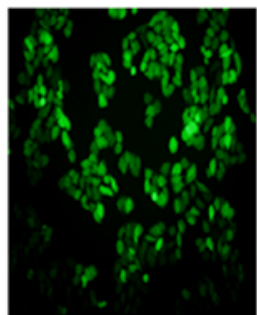

$20 \mu \mathrm{M}$

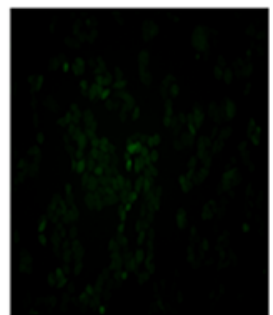

$20 \mu \mathrm{M}$ with NAC

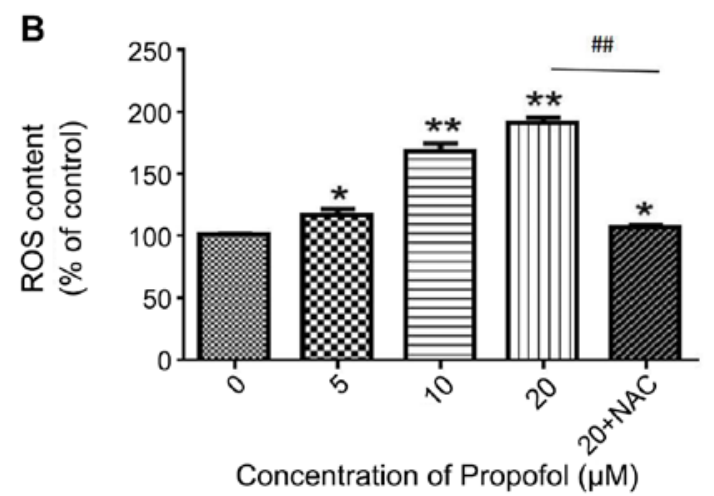

Figure 2. ROS generation in MDA-MB-468 cells is increased following propofol exposure. (A) Intracellular ROS production in MDA-MB-468 cells was measured using a DCF-DA assay. MDA-MB-468 cells were treated with PBS (control) or propofol $(5,10,20$ and $20 \mu \mathrm{M}+\mathrm{NAC})$ for $24 \mathrm{~h}$. Cellular ROS production was observed using an inverted fluorescence microscope. (B) Quantification of ROS production following propofol treatment. Data are presented as the mean $\pm \mathrm{SD}(\mathrm{n}=3) .{ }^{*} \mathrm{P}<0.05$ and ${ }^{* *} \mathrm{P}<0.01$ vs. the control group. Compared with the $20 \mu \mathrm{M}$ group, the $20 \mu \mathrm{M}+\mathrm{NAC}$ group showed a significant difference $\left({ }^{\# \#} \mathrm{P}<0.01\right)$. ROS, reactive oxygen species; NAC, N-acetyl-L-cysteine.

A

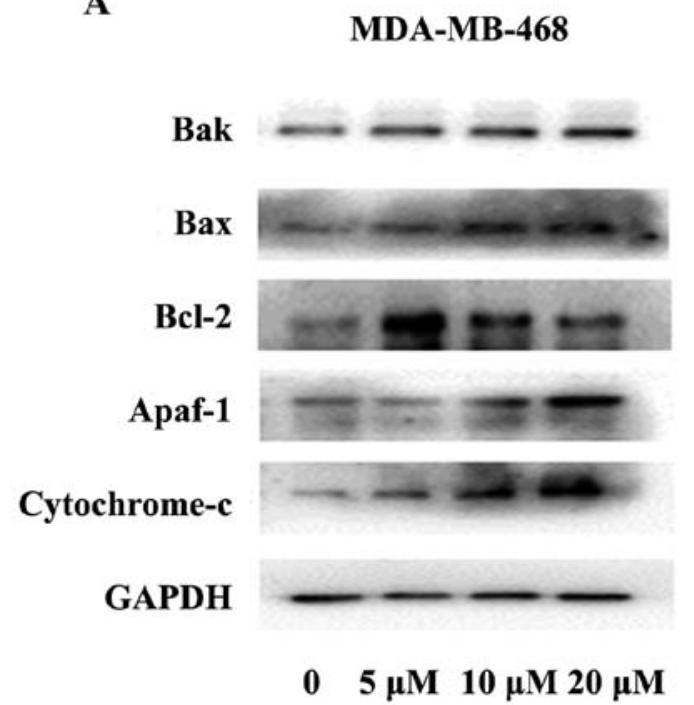

B

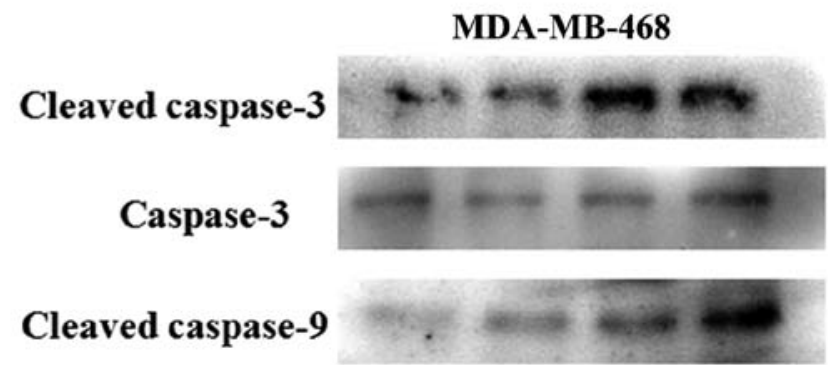

Caspase-9

Figure 3. MDA-MB-468 cells were treated with PBS (control) or propofol for 24 h. The expression levels of (A) Bak, Bax, Bcl-2, Cytochrome C, Apaf-1 and (B) Cleaved caspase- 3/9 and Caspase- 3/9 were measured by western blotting. In MDA-MB-468 cells treated with 5 , 10 and $20 \mu \mathrm{M}$ propofol for $24 \mathrm{~h}$, the protein expression of the apoptotic proteins Bax, Bak, Apaf-1 and Cytochrome $\mathrm{C}$ was upregulated compared with the control group treated with PBS for the same time. Similarly, propofol increased the expression of cleaved caspase- 3/9 in MDA-MB-468 cells in a dose-dependent manner. Propofol-induced Bcl-2 upregulation; however, expression was decreased at high concentrations. The ratio of Bax to Bcl-2 suggested that propofol has exhibits a proapoptotic effect. Figures showed that the GAPDH was used as an internal control. Data are presented as the mean \pm standard deviation ( $=3$ ). Apaf-1, apoptotic peptidase-activating factor 1 .

Effect of propofol on the level of cellular ROS. In order to examine the ROS accumulation induced by propofol, and fluorescence microscopy were used to measure the generation of intracellular ROS. The results demonstrated that propofol significantly induced ROS accumulation in
MDA-MB-468 cells in a dose-dependent manner, when compared with the control group treated with $\mathrm{PBS}(\mathrm{P}<0.05$; Fig. 2). In addition, treatment with $5 \mathrm{mM}$ NAC reduced the amount of ROS induced by $20 \mu \mathrm{M}$ propofol $(\mathrm{P}<0.01)$. The results demonstrated that the brighter cells appeared under 


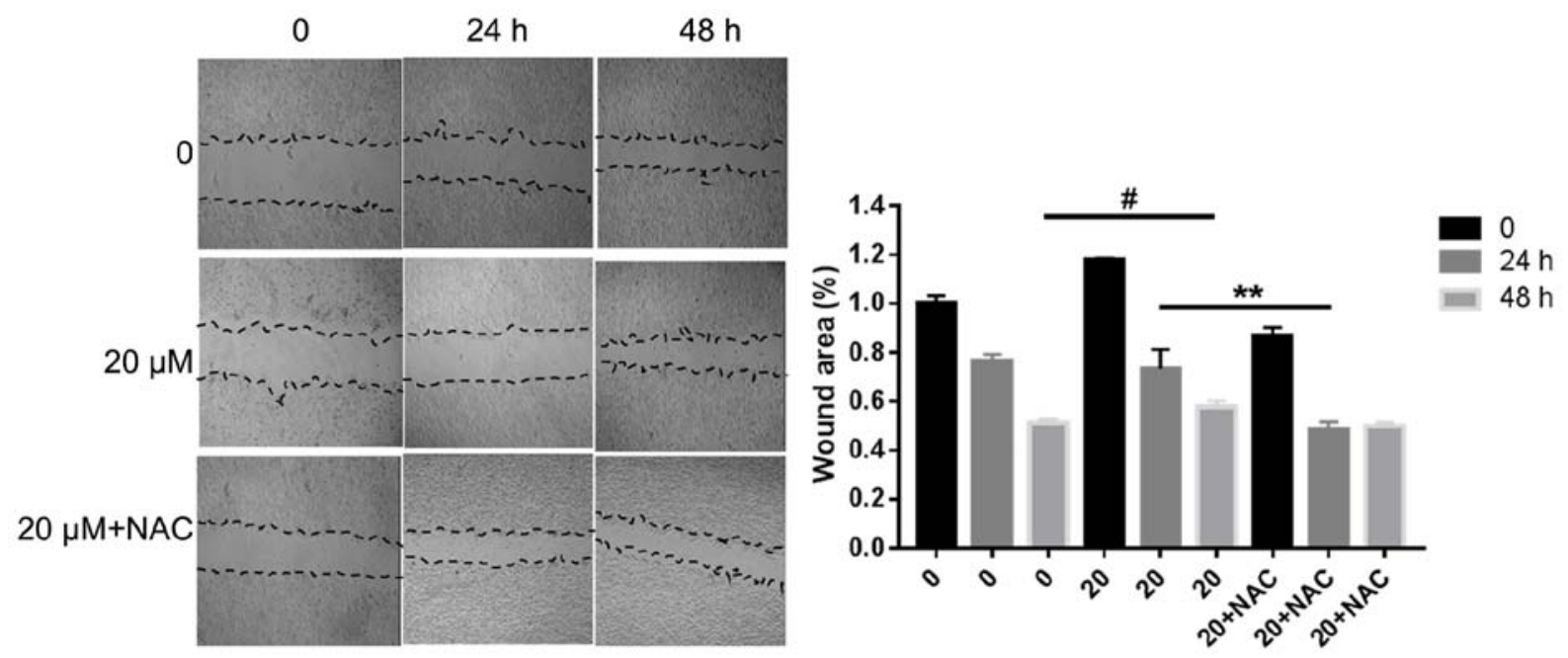

Figure 4. MDA-MB-468 cells were seeded in 6-well plates and allowed to reach a confluent monolayer. The cells were incubated with various concentrations of propofol for 0,24 or $48 \mathrm{~h}$. Cells were also incubated with $20 \mu \mathrm{M}$ propofol + NAC for $48 \mathrm{~h}$. (A) Wound healing assay and (B) analysis performed relative to the starting wound width at $0 \mathrm{~h}$. Data are represented as the mean $\pm \mathrm{SD}(\mathrm{n}=3) .{ }^{*} \mathrm{P}<0.05(0$ vs. $20 \mu \mathrm{M}$ propofol for $48 \mathrm{~h}){ }^{* * *} \mathrm{P}<0.01(20 \mu \mathrm{M}$ propofol vs. $20 \mu \mathrm{M}$ propofol + NAC for 48 h). NAC, N-acetyl-L-cysteine.

the inverted fluorescence microscope, the more ROS were produced, which was indicative of heavier damage to the cells.

Effect of propofol on the endogenous apoptotic pathway. As shown in Fig. 3A the expression of Bax and Bak was increased while that of Bcl-2 was decreased in cells treated with propofol $(\mathrm{P}<0.05)$. Apaf-1 and Cytochrome c were increased in a concentration-dependent manner after propofol treatment (Fig. 3B; P $<0.05$ ). Fig. 3B revealed that the expression of cleaved caspase- 3 and cleaved caspase-9 in MDA-MB-468 cells was increased in a concentration-dependent manner following treatment with propofol $(\mathrm{P}<0.05)$.

Effect of propofol on MDA-MB-468 cell migration. In order to examine the effect of propofol on MDA-MB-468 cell migration, a wound healing assay was performed. The experimental results revealed that the scratch distance became narrower and the scratch area became smaller in a dose and time-dependent manner $(\mathrm{P}<0.05)$. However, treatment with $5 \mathrm{mM}$ NAC partially reversed the effect of $20 \mu \mathrm{M}$ propofol. The analysis was performed relative to the starting wound width at $0 \mathrm{~h}$. The results shown in Fig. 4 suggested that propofol promoted the migration of MDA-MB-468 cells.

\section{Discussion}

The treatment of TNBC is challenging due to its aggressiveness, cellular and histological heterogeneity and complexity of its molecular mechanisms (24). Recent studies have demonstrated that, not only do certain anesthetics function as sedatives and analgesics, but can also serve a pivotal role in antitumor and immunoregulation (25). Among these, propofol has been the focus of an increasing amount of interest, due to its correlative studies. The active component in propofol is 2, 6-diisopropylphenol (26). The present study investigated the effect of propofol on the proliferation and apoptosis of
MDA-MB-468 cells, and attempted to elucidate the underlying molecular mechanism of action.

The results of the present study revealed that propofol inhibited proliferation and promoted the ROS-mediated endogenous apoptosis pathway in MDA-MB-468 cells. Initially, cell proliferation was inhibited following treatment with propofol; however, this effect was reversed by NAC. In addition, the rate of apoptosis was increased with increasing propofol concentration, and $5 \mathrm{mM}$ NAC attenuated apoptosis induced by $20 \mu \mathrm{M}$ propofol. The present study examined the expression of important proteins in the endogenous apoptotic pathway. It is well established that there are two general categories of apoptotic pathways, namely endogenous and exogenous. In the endogenous apoptotic pathway, Cytochrome $c$ is released into the cytoplasm by enhanced mitochondrial transition pore opening under the effect of drugs. Cytochrome $c$ in the cytoplasm combines with Apaf-1, contributing to the formation of a polymer (27). There is an upstream and downstream relationship between the initiators of apoptosis (Caspase 2, 8, 9 and 10) and the executors (Caspase 3, 6 and 7), and a previous study demonstrated that the initiators could activate the executors (28). Caspase 3 and Caspase 9 are closely associated with apoptosis, and once apoptosis is initiated, the caspase cascade is initiated by apoptotic proteases, which induces irreversible apoptosis. Apoptosis is strictly regulated, and the normal cell caspases are in the non-activated zymogen state (29). In the present study, following treatment with propofol, the expression of the pro-apoptotic protein Bax, was increased, and as the concentration of propofol was increased, the apoptotic effect was enhanced accordingly. Notably, the level of Bcl-2 was increased with $5 \mu \mathrm{M}$ propofol; however, the expression of $\mathrm{Bcl}-2$ was decreased when cells were treated with 10 and $20 \mu \mathrm{M}$ propofol. It was hypothesized that propofol may partially result in the activation of antiapoptotic systems at a concentration of $5 \mu \mathrm{M}$.

ROS generated by cellular metabolism readily oxidize adjacent molecules and participate in various signal transduction pathways in cells (30). An excessive amount of ROS can cause oxidative damage to important molecules in the cell. When ROS 
are excessively produced, or ROS scavenging is reduced, the redox level is unbalanced, resulting in oxidative stress damage to the body (31). In the present study, the level of ROS increased with increasing concentrations of propofol, and NAC reduced the level of ROS. ROS may promote the formation of a monolayer on the mitochondrial surface of the antiapoptotic protein $\mathrm{Bcl}-2$, and activates the proapoptotic protein Bax, which results in the formation of pores in the mitochondrial membranes, resulting in the leakage of Cytochrome $c$. Cytochrome $c$ binds to Apaf-1 to form apoptotic bodies, which then bind to and activate Caspase-9, leading to cell death (32). Apoptosis and cell proliferation are essential cellular processes, and are also the basic measurements used to evaluate cell dynamics and cell numbers in vivo $(33,34)$. The present study investigated the effect of propofol on the migration MDA-MB-468 and revealed that propofol increased migration. It has been confirmed that ROS from various sources serve an important role in the malignant proliferation and migration of tumor cells; however, its mechanism of action has not been completely elucidated $(35,36)$. ROS may activate ataxia telangiectasia mutated directly or indirectly, thereby activating IL-8 and promoting tumor cell migration (37).

To the best of our knowledge, the present study was the first to report that propofol may promote the activation of the endogenous apoptotic pathway by inducing the production of ROS, leading to decreased MDA-MB-468 cell proliferation and increased migration. The results suggested that propofol may be a promising therapeutic choice for patients with TNBC following surgery. Future studies should explore whether there are other signaling pathways and molecules involved in the effects of propofol on apoptosis and migration in TNBC cells, and whether it has an antitumor effect in the body. Once this information is obtained and verified, propofol may be considered for use as an anticancer agent in the clinical setting.

\section{Acknowledgements}

Not applicable.

\section{Funding}

The present study was funded by the project from Shanghai Municipal Health Commission and Shanghai Municipal Administrator of Traditional Chinese Medicine Planning (grant no. ZY(2018-2020) CCCX-1002), the Shanghai Foundation for Development of Science and Technology (grant no. 17401901200), the National Natural Science Foundation of China (grant no. 81570293) and the Scientific Research Foundation of Shanghai Songjiang District Committee of Science and Technology (grant no. 2019sjkjgg012).

\section{Availability of data and materials}

The datasets used and/or analyzed during the present study are available from the corresponding author upon reasonable request.

\section{Authors' contributions}

SW and JH designed the present study. HW, LZ and JW performed the experiments, while HW, LZ and JH analyzed the data. HW, LZ and SW drafted the initial manuscript. All authors read and approved the final manuscript.

\section{Ethics approval and consent to participate}

Not applicable.

\section{Patient consent for publication}

Not applicable.

\section{Competing interests}

The authors declare that they have no competing interests.

\section{References}

1. Ha GH, Kim DY, Breuer EK and Kim CK: Combination treatment of polo-like kinase 1 and tankyrase-1 inhibitors enhances anticancer effect in triple-negative breast cancer cells. Anticancer Res 38: 1303-1310, 2018.

2. Wahdan-Alaswad R, Fan Z, Edgerton SM, Liu B, Deng XS, Arnadottir SS, Richer JK, Anderson SM and Thor AD: Glucose promotes breast cancer aggression and reduces metformin efficacy. Cell Cycle 12: 3759-3769, 2013.

3. Yardley DA, Brufsky A, Coleman RE, Conte PF, Cortes J, Gluck S, Nabholtz JM, O'Shaughnessy J, Beck RM, Ko A, et al: Phase II/III weekly nab-paclitaxel plus gemcitabine or carboplatin versus gemcitabine/carboplatin as first-line treatment of patients with metastatic triple-negative breast cancer (the tnAcity study): Study protocol for a randomized controlled trial. Trials 16: 575, 2015.

4. Lukong KE, Ogunbolude Y and Kamdem JP: Breast cancer in Africa: Prevalence, treatment options, herbal medicines, and socioeconomic determinants. Breast Cancer Res Treat 166: 351-365, 2017.

5. Abdulrahman GJ Jr and Rahman GA: Epidemiology of breast cancer in europe and Africa. J Cancer Epidemiol 2012: 915610, 2012.

6. Aziz H, Hussain F, Sohn C, Mediavillo R, Saitta A, Hussain A, Brandys M, Homel P and Rotman M: Early onset of breast carcinoma in African American women with poor prognostic factors. Am J Clin Oncol 22: 436-440, 1999.

7. Cao J, Chen Z, Chi J, Sun Y and Sun Y: Recent progress in synergistic chemotherapy and phototherapy by targeted drug delivery systems for cancer treatment. Artif Cells Nanomed Biotechnol 46: 817-830, 2018.

8. Wilson TR, Udyavar AR, Chang CW, Spoerke JM, Aimi J, Savage HM, Daemen A, O'Shaughnessy JA, Bourgon R and Lackner MR: Genomic Alterations Associated with recurrence and TNBC subtype in high-risk early breast cancers. Mol Cancer Res 17: 97-108, 2019.

9. Kay B and Rolly G: I.C.I. 35868, a new intravenous induction agent. Acta Anaesthesiol Belg 28: 303-316, 1977.

10. Dietrich SK, Mixon MA, Rogoszewski RJ, Delgado SD, Knapp VE, Floren M and Dunn JA: Hemodynamic effects of propofol for induction of rapid sequence intubation in traumatically injured patients. Am Surg 84: 1504-1508, 2018.

11. Vasileiou I, Xanthos T, Koudouna E, Perrea D, Klonaris C, Katsargyris A and Papadimitriou L: Propofol: A review of its non-anaesthetic effects. Eur J Pharmacol 605: 1-8, 2009.

12. Sekandarzad MW, van Zundert AAJ, Lirk PB, Doornebal CW and Hollmann MW: Perioperative anesthesia care and tumor progression. Anesth Analg 124: 1697-1708, 2017.

13. Tan Z, Peng A, Xu J and Ouyang M: Propofol enhances BCR-ABL TKIs' inhibitory effects in chronic myeloid leukemia through Akt/mTOR suppression. BMC Anesthesiol 17: 132, 2017.

14. Huang X, Teng Y, Yang H and Ma J: Propofol inhibits invasion and growth of ovarian cancer cells via regulating miR-9/NF- $\mathrm{B}$ signal. Braz J Med Biol Res 49: e5717, 2016.

15. Yang C, Gao J, Yan N, Wu B, Ren Y, Li H and Liang J: Propofol inhibits the growth and survival of gastric cancer cells in vitro through the upregulation of ING3. Oncol Rep 37: 587-593, 2017. 
16. Liu Z, Zhang J, Hong G, Quan J, Zhang L and Yu M: Propofol inhibits growth and invasion of pancreatic cancer cells through regulation of the miR-21/Slug signaling pathway. Am J Transl Res 8: 4120-4133, 2016.

17. Li Q, Zhang L, Han Y, Jiang Z and Wang Q: Propofol reduces MMPs expression by inhibiting NF- $\kappa \mathrm{B}$ activity in human MDA-MB-231 cells. Biomed Pharmacother 66: 52-56, 2012.

18. Yang N, Liang Y, Yang P and Ji F: Propofol suppresses LPS-induced nuclear accumulation of HIF- $1 \alpha$ and tumor aggressiveness in non-small cell lung cancer. Oncol Rep 37: 2611-2619, 2017.

19. Zhang W, Wang Y, Zhu Z, Zheng Y and Song B: Propofol inhibits proliferation, migration and invasion of gastric cancer cells by up-regulating microRNA-195. Int J Biol Macromol 120: 975-984, 2018

20. Du QH, Xu YB, Zhang MY, Yun P and He CY: Propofol induces apoptosis and increases gemcitabine sensitivity in pancreatic cancer cells in vitro by inhibition of nuclear factor- $\kappa \mathrm{B}$ activity. World J Gastroenterol 19: 5485-5492, 2013.

21. Meng C, Song L, Wang J, Li D, Liu Y and Cui X: Propofol induces proliferation partially via downregulation of $\mathrm{p} 53$ protein and promotes migration via activation of the Nrf2 pathway in human breast cancer cell line MDA-MB-231. Oncol Rep 37: 841-848, 2017

22. Bai JJ, Lin CS, Ye HJ, Guo PP and Wang W: Propofol suppresses migration and invasion of breast cancer MDA-MB-231 cells by down-regulating H19. Nan Fang Yi Ke Da Xue Xue Bao 36: 1255-1259, 2016 (in Chinese).

23. Grandhi RK, Lee S and Abd-Elsayed A: The relationship between regional anesthesia and cancer: A metaanalysis. Ochsner J 17: 345-361, 2017.

24. Rodriguez BR, Ortega GA, Hidalgo MA, Zentella DA, Villarreal-Garza C, Avila-Moreno F and Arrieta O: Long non-coding RNAs: Implications in targeted diagnoses, prognosis, and improved therapeutic strategies in human non- and triple-negative breast cancer. Clin Epigenetics 10: 88, 2018.

25. Li R, Liu H, Dilger JP and Lin J: Effect of Propofol on breast Cancer cell, the immune system, and patient outcome. Bmc Anesthesiol 18: 77, 2018.

26. Baker MT: The anticonvulsant effects of propofol and a propofol analog, 2,6-diisopropyl-4-(1-hydroxy-2,2,2-trifluoroethyl) phenol, in a $6 \mathrm{~Hz}$ partial seizure model. Anesth Analg 112 340-344, 2011
27. Cai J, Yang J and Jones DP: Mitochondrial control of apoptosis: The role of cytochrome c. Biochim Biophys Acta 1366: 139-149, 1998.

28. McIlwain DR, Berger T and Mak TW: Caspase functions in cell death and disease. Cold Spring Harb Perspect Biol 7: pii: a026716, 2015.

29. Kopeina GS, Prokhorova EA, Lavrik IN and Zhivotovsky B: Alterations in the nucleocytoplasmic transport in apoptosis: Caspases lead the way. Cell Prolif 51: e12467, 2018.

30. Bernatoniene J and Kopustinskiene DM: The role of catechins in cellular responses to oxidative stress. Molecules 23: pii: E965, 2018.

31. Kim HS, Kim YJ and Seo YR: An overview of carcinogenic heavy metal: Molecular Toxicity mechanism and prevention. J Cancer Prev 20: 232-240, 2015.

32. Seervi M, Rani A, Sharma AK and Santhosh Kumae TR: ROS mediated ER stress induces Bax-Bak dependent and independent apoptosis in response to Thioridazine. Biomed Pharmacother 106: 200-209, 2018.

33. Fink SL and Cookson BT: Apoptosis, pyroptosis, and necrosis: Mechanistic description of dead and dying eukaryotic cells. Infect Immun 73: 1907-1916, 2005.

34. Lai ZC, Wei X, Shimizu T, Ramos E, Rohrbaugh M, Nikolaidis N, Ho LL and Li Y: Control of cell proliferation and apoptosis by mob as tumor suppressor, mats. Cell 120: 675-685, 2005.

35. Lin XL, Yang L, Fu SW, Lin WF, Gao YJ, Chen HY and Ge ZZ: Overexpression of NOX4 predicts poor prognosis and promotes tumor progression in human colorectal cancer. Oncotarget 8: 33586-33600, 2017.

36. Park GB and Kim D: PI3K catalytic isoform alteration promotes the LIMK1-related metastasis through the PAK1 or ROCK1/2 activation in cigarette smoke-exposed ovarian cancer cells. Anticancer Res 37: 1805-1818, 2017.

37. Chen WT, Ebelt ND, Stracker TH, Xhemalce B, Van Den Berg CL and Miller KM: ATM regulation of IL-8 links oxidative stress to cancer cell migration and invasion. Elife 4, 2015.

This work is licensed under a Creative Commons Attribution-NonCommercial-NoDerivatives 4.0 International (CC BY-NC-ND 4.0) License. 